\title{
Memory for Information Perceived Without Awareness
}

\author{
Philip M. Merikle ${ }^{1}$ and Stephen D. Smith ${ }^{2}$ \\ ${ }^{1}$ University of Waterloo, Canada \\ ${ }^{2}$ Vanderbilt University, USA
}

\begin{abstract}
Summary. What is the duration of the influence of information perceived without awareness? Some studies suggest a duration of only a few seconds whereas others suggest a duration of hours, days, or weeks. To further investigate this question, we used a variant of the inattentional blindness paradigm (Mack \& Rock, 1998). In three experiments, participants viewed briefly presented visual displays consisting of both a centrally located word and a peripherally located cross with unequal vertical and horizontal arms. Awareness of the words was varied by requiring participants either to read the word and then judge which arm of the cross was longer, or the reverse. Perception of the words was assessed using three-letter stems (e.g., pho___ ) of each word (e.g., phone), with participants instructed to complete the stem to make any word other than one previously presented. Success in following the instructions indicates that a word was perceived with awareness; failure indicates that a word was perceived without awareness. Memory for information perceived without awareness lasted for at least 32 minutes, and was strong following all retention intervals. These findings are consistent with previous studies suggesting that memory for information perceived without awareness can last for hours or days.
\end{abstract}

Key words. Awareness, memory, consciousness, anaesthesia,, inattentional blindness

\section{Introduction}

What is the duration of information perceived without awareness? This is a critically important question. Given that perception without awareness is now a firmly established phenomenon (see Merikle, Smilek, \& Eastwood, 2001), an answer to this question is relevant for deciding just how important an influence perception without awareness may be on the way people 
consciously experience the world. If the influence of perception without awareness only lasts for a few seconds, then perception without awareness may not have particularly important consequences. In contrast, if the influence or impact of perception without awareness lasts for hours or days, then perception without awareness may have important consequences regarding how people consciously experience the world about them.

In this chapter, we first describe a series of experiments in which the duration of the impact of information perceived without awareness was assessed over retention intervals ranging from a few seconds to 32 minutes. The results of these experiments show that information perceived without awareness persists in memory for at least 32 minutes, and suggest that information perceived without awareness may persist in memory for considerably longer periods of time. We next review the evidence from studies of memory for information presented to surgical patients during general anaesthesia. The results of these studies show that memory for information perceived without awareness can last for hours or even days following surgery. Thus, the evidence from two very different types of studies shows that information perceived without awareness can persist in memory for considerable periods of time.

Finally, we consider why the findings from other studies (e.g., Greenwald, Draine, \& Abrams, 1996) suggest that the impact of information perceived without awareness may only persist in memory for periods of time lasting no more than a second. We suggest that these very different conclusions are the consequence of the way awareness is measured. In our studies and in studies of memory for events during anaesthesia, awareness was assessed using subjective measures, whereas in other studies, awareness has been assessed using objective measures. We suggest that subjective measures provide a more accurate measure of the presence or absence of awareness than is provided by objective measures.

\section{Studies of memory for information perceived without awareness}

Our studies were based on a methodology adapted from Mack and Rock's (1998) studies of inattentional blindness. Figure 1 shows examples of the displays used by Mack and Rock in many of their studies. On each trial, participants viewed a series of three displays: fixation, stimulus, and mask. Each stimulus display contained a cross with either a longer vertical or a longer horizontal arm presented in one of the quadrants. Both the location of the cross and the arm which was longer varied randomly on each trial. 

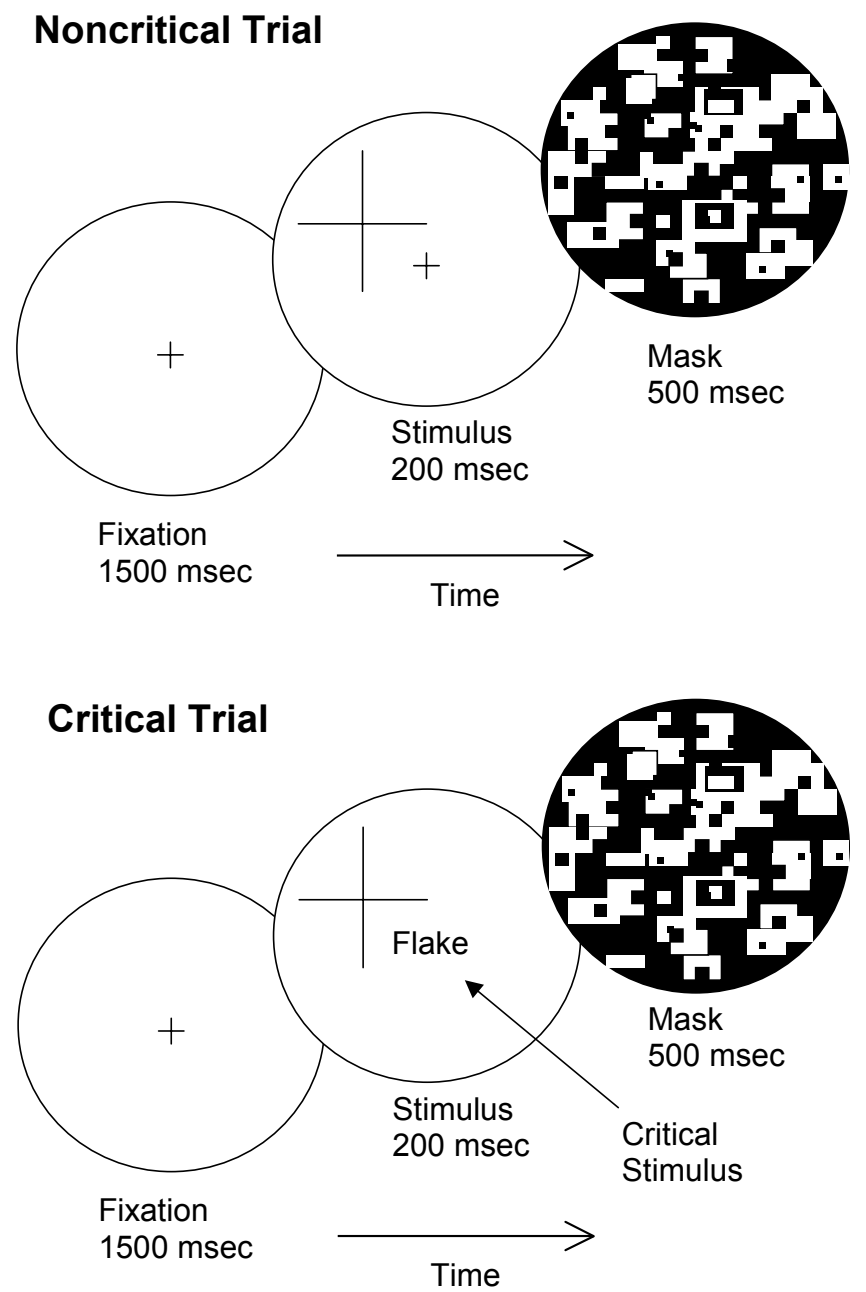

Fig. 1. Illustration of the stimulus displays used by Mack and Rock in many of their studies of inattentional blindness (adapted from Mack \& Rock, 1998, p. 16).

The participants' task was simply to state which arm of the cross (i.e., horizontal or vertical) was longer. In a typical experiment, the first two trials in a series of three trials would be noncritical trials with only a cross in one quadrant of each stimulus display. On the third or critical trial, in addition to the cross, each stimulus display also contained a critical stimulus presented at fixation (e.g., a word). On all critical trials, once the participants indicated which arm of the cross was longer, they were asked if they had seen anything other than the cross on the trial. Surprisingly, 
across a number of experiments, anywhere from 50 to $60 \%$ of the participants failed to notice the critical stimulus at fixation. It is these failures to notice critical stimuli that defines inattentional blindness.

Mack and Rock (1998) conducted a series of experiments in which a single word was presented at fixation on critical trials. On average, $62.5 \%$ of the participants failed to notice the word. Mack and Rock interpreted this finding as indicating an absence of any conscious awareness of the words. They then sought to determine whether there was implicit knowledge of the words despite the participants' failures to notice the words. To test for implicit knowledge, Mack and Rock used the stem-completion task. On critical trials, once a participant indicated which arm of the cross was longer and stated whether they noticed anything in the center of the display, Mack and Rock presented the three-letter stem of the word presented on that trial. For example, if the word flake had been presented, then the word stem that followed was fla _ . The participants were asked to complete the word stem with the first two words that came to mind.

Not surprisingly, the results indicated the $95 \%$ of the participants who noticed a word on the critical trial used it as one of their stem completions. More importantly, $36 \%$ of the participants who claimed not to have seen a word or any other stimulus at fixation on the critical trial also used the word to complete the stem. Given that the baseline level of performance for completing the stems with the critical words was $8 \%$, these findings indicate that the participants had some implicit knowledge of the critical word even when they claimed not to have seen it. Thus, the results of these experiments provide strong evidence that at least some of the critical words were perceived without awareness.

Our experiments had two important differences relative to the experiments conducted by Mack and Rock (1998). First, in the majority of Mack and Rock's experiments, there was a single critical trial. This was to ensure that conditions of inattention were met. In contrast, we presented each participant with multiple critical trials. Mack and Rock assumed that conditions of inattention must be met to ensure that participants were unaware of the critical stimuli. However, conditions of inattention are not necessary for perception without awareness to occur. Merikle and Joordens (1997) showed that simply dividing participants' attention is sufficient to produce perception without awareness. Thus, as long as attention is divided between the cross and the critical stimulus, it should be possible to examine perception without awareness using multiple trials and displays similar to those used by Mack and Rock.

The second important difference between our experiments and Mack and Rock's experiments was that we assessed memory with a stemcompletion task coupled with exclusion instructions rather than with a 
stem-completion task coupled with instructions asking participants to complete the stems with the first word that came to mind. With exclusion instructions, participants are asked to complete the stems with any word other than a word that they may have seen in the stimulus displays. The basic assumption underlying exclusion instructions is that whenever a critical stimulus word is perceived with awareness, participants will follow the instructions and not use the word to complete a stem. In contrast, whenever a critical stimulus word is perceived without awareness, participants may use the word to complete a stem because they have no awareness of ever having perceived the word during the experiment. Exclusion instructions have been used successfully in previous experiments to distinguish perception with awareness from perception without awareness (e.g., Merikle, Joordens, \& Stolz, 1995). Perception with awareness is implied whenever participants successfully follow the instructions and do not use the words in the displays to complete the stems. An important consequence of following the exclusion instructions is that the number of failures to follow the instructions falls below the baseline level of performance. In contrast, perception without awareness is implied whenever participants fail to follow the exclusion instructions and use the words in the displays to complete the stems. The consequence of not following the instructions is that the number of failures to follow the instructions is above the baseline level of performance.

The real advantage of using a stem-completion task in conjunction with exclusion instructions is that perception with awareness and perception without awareness lead to different patterns of findings relative to the baseline level of performance. Perception with awareness leads to performance below the baseline level, whereas perception without awareness leads to performance above the baseline level. These qualitatively different patterns of data make it relatively easy to distinguish conditions which lead to perception with awareness from conditions which lead to perception without awareness. In contrast, when participants are simply asked to compete stems with the first word that comes to mind, it is not possible to distinguish perception with awareness from perception without awareness because both types of perception lead to increases in the number of word stems completed using words that appeared in the stimulus displays. It is for these reasons that we used a stem-completion task coupled with exclusion instructions in our studies investigating memory for information perceived without awareness.

In our first experiment, the goal was simply to establish whether our adaptation of the Mack and Rock (1998) methodology could be used to study perception without awareness. Figure 2 shows examples of the trial se- 


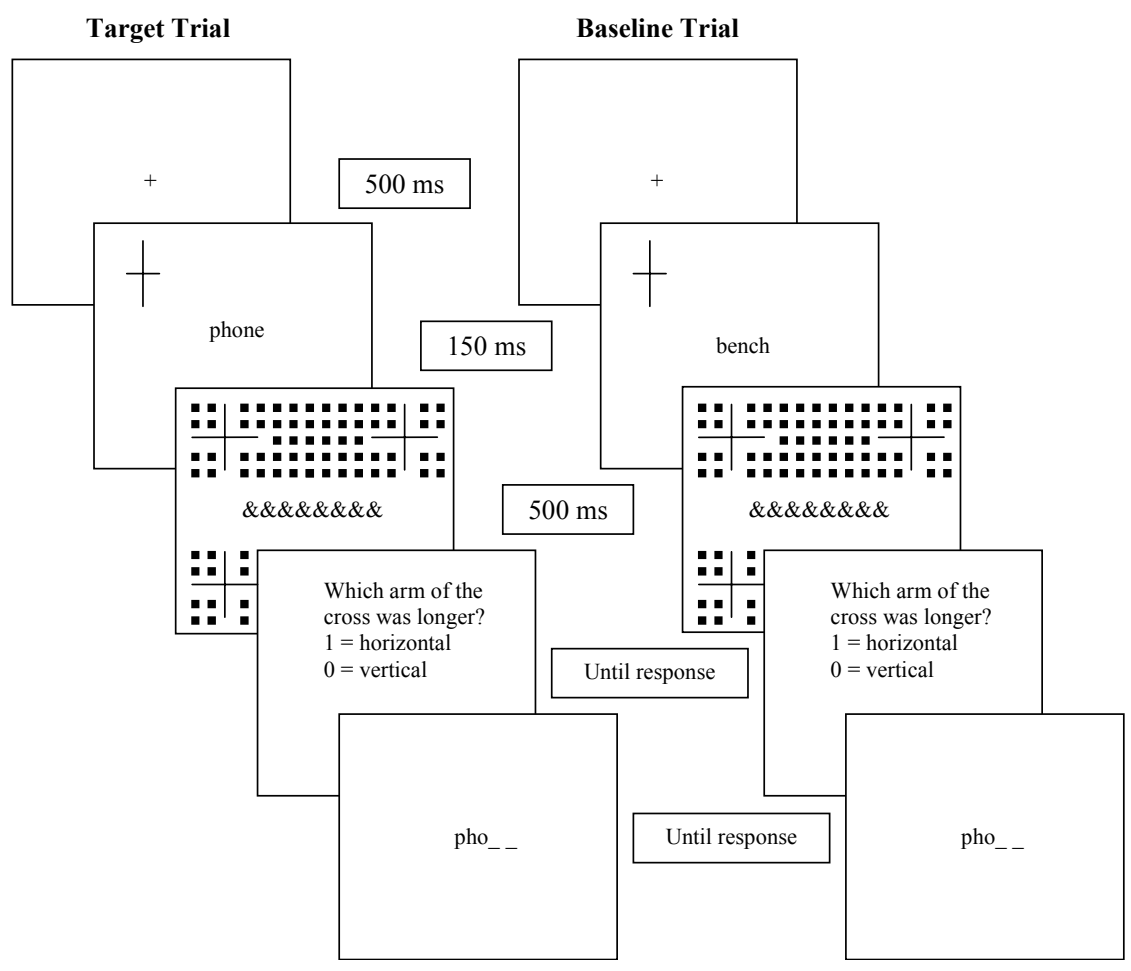

Fig. 2. Examples of the sequence of events on target and baseline trials.

quences used in this study. On each trial, a single display containing both a peripherally located cross and a centrally located, five-letter word was presented for $150 \mathrm{~ms}$. The participants were instructed to perform two tasks. Half of the participants were instructed to first read the word and then to decide, if possible, whether the horizontal or vertical arm of the cross was longer. For these participants, the instructions placed the primary emphasis on reading the words and the expectation was that the participants would perceive most if not all of these words with awareness. In contrast, for the other half of the participants, the instructions were reversed: These participants were instructed to first decide which arm of the cross was longer and then to read the word, if possible. Given previous findings showing that divided attention leads to perception without awareness (e.g., Debner \& Jacoby, 1994; Merikle \& Joordens, 1997), it was ex- 
pected that in many instances the words would be perceived without awareness because the primary emphasis was placed on judging the arms of the cross.

Following the presentation of each display, the participants were presented with two tasks. First, as shown in Figure 2, they were asked to decide whether the horizontal or vertical arm of the cross was longer. Once the participants made their decision regarding the cross, they were presented with a three-letter stem. On target trials, the stem consisted of the first three letters of the word that had been presented in the display. On baseline trials, the same three-letter stem was presented but it was preceded by a word other than the target. All participants were instructed to complete the stems to make any five-letter word except a word that had been presented in the stimulus displays. The expectation was that perception of the words with awareness would bias participants not to use the words to complete the stems, whereas perception of the words without awareness would bias participants to use the words to complete the stems.

The results of Experiment 1 are shown in Figure 3. The dotted line in the figure indicates how often the word stems were completed to make the target word on baseline trials when the target word was not presented. As indicated in the figure, the baseline completion rate was approximately $21 \%$. Relative to this baseline, it can be seen that when the participants focused their attention on the target words (read words first), they were very successful in excluding the target words from their completions of the word stems. On these trials, the stems were completed with target words significantly less often than the stems were completed with target words on baseline trials. Given the logic underlying the exclusion instructions, this finding indicates that when the participants focussed their attention on the target words, they were generally aware of the target words. In contrast, it can also be seen in Figure 3 that when the participants focussed their attention on the crosses (judge cross arm length first), they failed to exclude the target words from their stem completions on more than $35 \%$ of the trials. The participants used target words to complete the stems on these trials significantly more often than they completed the stems on baseline trials with target words. The logic underlying the exclusion instructions leads to the conclusion that the target words were perceived without awareness on many trials.

The pattern of results found in Experiment 1 shows that it is possible to use a multi-trial adaptation of Mack and Rock's (1998) methodology to study perception without awareness. In a manner consistent with previous findings (e.g., Debner \& Jacoby, 1994; Merikle \& Joordens, 1997), when the participants read the target word and then judged which arm of the cross was longer, they generally were able to show that they were aware of 


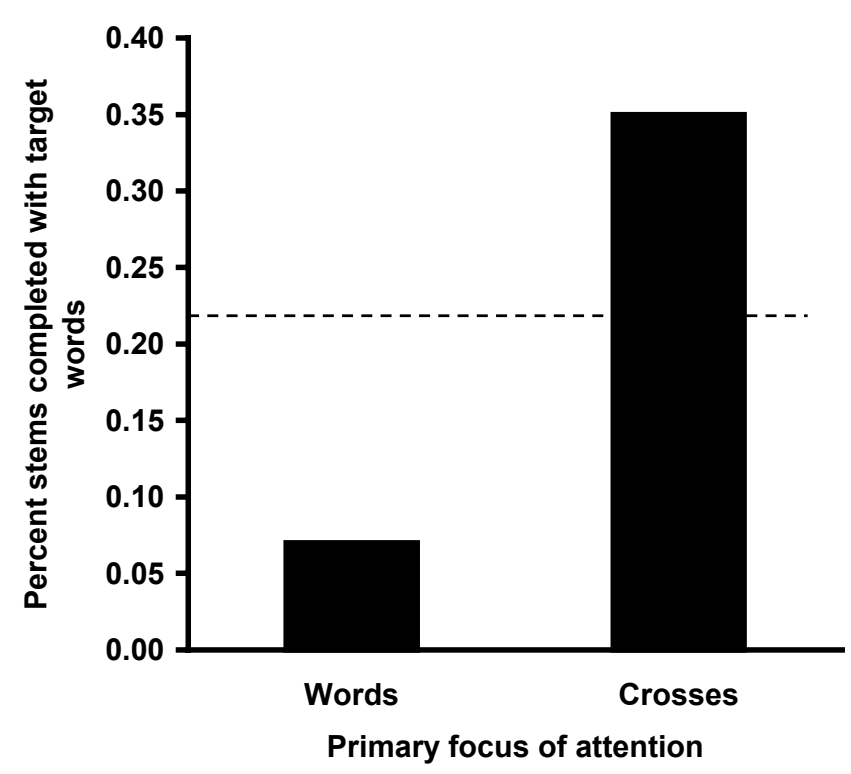

Fig. 3. Experiment 1: Percent of stems completed with target words when attention to the displays was focussed on the words and on the crosses. Dotted line indicates the baseline level of performance.

the target word by completing the word stem with a word other than the target word. In contrast, when the participants first judged which arm of the cross was longer and then attempted to read the word, they were often unable to exclude the target words as completions for the word stems. This pattern of findings suggests that the participants were generally unaware of the words under this condition.

In our second experiment, we used the multi-trial adaptation of the Mack and Rock (1998) methodology to assess memory for information perceived without awareness following a 0 -sec and a 25 -sec retention interval. To create the 25 -sec retention interval, we inserted seven filler trials between the initial trial when the target word was presented at fixation and the test trial when a stem consisting of the first three letters of the target word was presented. The filler trials were as illustrated in Figure 2, except that neither a word nor a stem was presented. In other words, on each filler trial, the participants were presented the fixation cross, a display with a cross in one quadrant, the mask, and the question, Which arm of the cross was longer? Thus there were two trial types in Experiment 2: trials with no delay between presentation of the target word and presentation of 
the target word's stem (i.e., 0 -sec retention interval), and trials with seven filler trials between presentation of the target word and presentation of the target word's stem (i.e., 25-sec retention interval).

A second major change introduced in Experiment 2 was that on each trial other than the filler trials, the participants were asked to assess and to report their subjective awareness of the target word. Immediately after the participants indicated which arm of the cross was longer, they were shown a second question on the monitor screen. The second question asked How much of the word did you see? There were three possible replies to this question: (a) I saw the entire word, (b) I saw a few letters of the word, or (c) I saw no part of the word. The participants indicated their decision on each trial by pressing an appropriate key on the keyboard. This assessment of each participant's subjective awareness of each target word was used to classify whether a word was perceived with awareness or perceived without awareness. In this way, it was possible to separate memory for information perceived without awareness from memory for information perceived with awareness.

Before the results were analyzed, all trials were classified as aware or unaware trials based on the participants' assessments of their subjective awareness. Aware trials were those trials on which the participants indicated that they saw an entire word (60\% of the trials). Unaware trials were those trials on which the participants indicated either that they saw no part of the word (15\% of the trials) or that they saw a few letters in the word ( $25 \%$ of the trials). The justification for considering trials on which the participants' assessment of their subjective awareness was that they perceived a few letters in the word as unaware trials was based on two considerations. First, by their own assessments of their awareness, the participants were unaware of the word and were only aware of a few of the letters in the word. Second, and perhaps not surprisingly, given that the participants were unaware of the complete word, the patterns of findings for the two types of unaware trials were virtually identical at both the 0 -sec and $25-\mathrm{sec}$ retention intervals.

The results of Experiment 2 are shown in Figure 4. Once again, the dotted line in the figure indicates the baseline level of performance. Looking first at the 0 -sec retention interval, it can be seen that for words perceived with awareness, as indicated by the participants' own assessments of their awareness, it was possible for the participants to exclude most of these words from their completions of the word stems. This finding is of course what should occur when words are perceived with awareness. In contrast, for words perceived without awareness, as indicated by the participants' assessments of their awareness, it was much more difficult for the partici- 


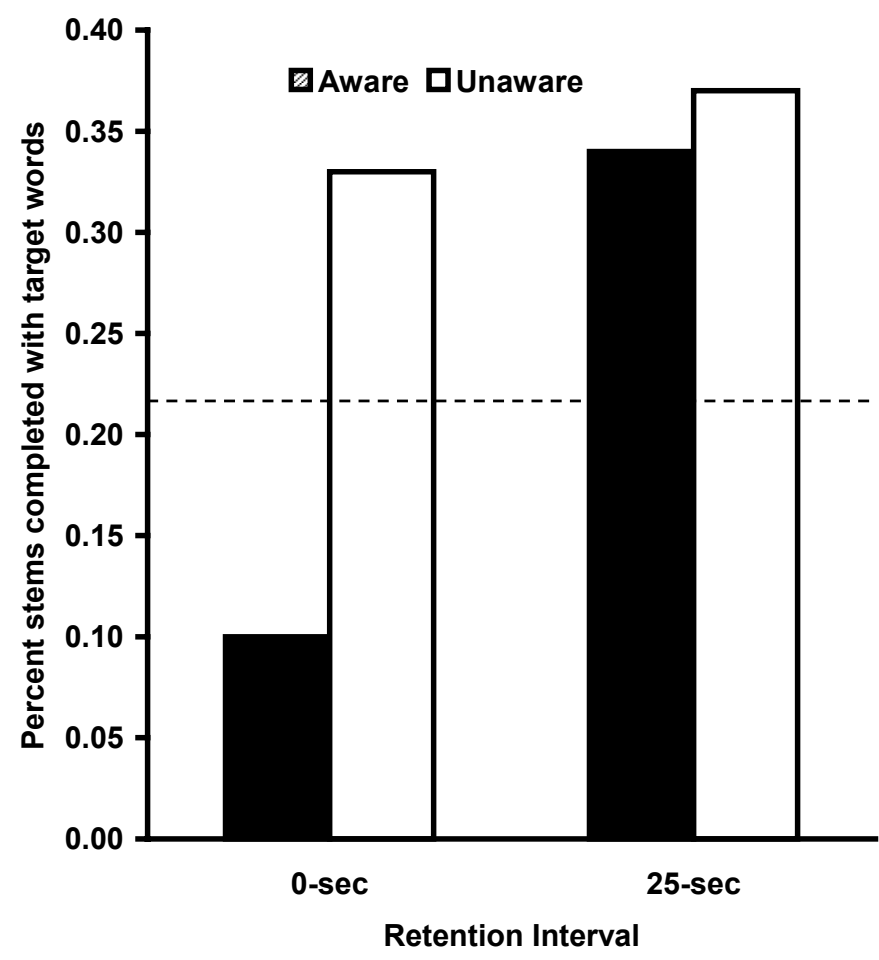

Fig. 4. Experiment 2: Percent of stems completed with target words following the 0 -sec and 25-sec retention intervals. Dotted line indicates the baseline level of performance.

pants to exclude these words from their stem completions. As shown in Figure 4, on these trials, the participants used the target words to complete the stems considerably more often than the target words were used on baseline trials. This finding is completely consistent with the idea that these words were perceived without awareness.

The participants' performance at the 25-sec retention interval shows two important findings. First, with regard to the primary question addressed by the experiment, the findings clearly show that there was memory for information perceived without awareness following the 25 -sec retention interval. Second, the findings show that the participants' ability to exclude words perceived with awareness from their stem completions dissipated rapidly. After only 25 seconds, there was no advantage for excluding words perceived with awareness relative to excluding words perceived 
without awareness. Thus, following the 25 -sec retention interval, performance was influenced in similar ways by memory for words perceived with awareness and by memory for words perceived without awareness.

Given the success of Experiment 2 in demonstrating memory for information perceived without awareness, we were encouraged to assess memory following considerably longer retention intervals. In Experiment 3, there were three retention intervals: 0-min, 16-min, and 32-min. The experiment was similar to Experiment 2 with the following two exceptions. First, no filler trials were included. Rather, all trials were as illustrated in Figure 2 in that, on each trial, both a word and a word stem were presented. The retention intervals were established by varying the number of trials between the presentation of each word and the presentation of that word's corresponding word stem. The second change in Experiment 3 was that the duration of the displays containing the cross and the target word was shortened from $150 \mathrm{~ms}$ to $100 \mathrm{~ms}$. This change was instituted to make the proportions of aware and unaware trials, as indicated by the participants reports of their experiences, more equivalent.

The results of Experiment 3 are shown in Figure 5. Again, the dotted line in the figure indicates the baseline level of performance. What is clear from an inspection of Figure 5 is that the overall pattern of findings is very similar to the pattern of findings in Experiment 2. Namely, at the shortest retention interval (i.e., $0 \mathrm{~min}$ ), participants were generally able to exclude the target words from their stem completions when they were aware of the words at the time they were presented. However, participants were generally unable to exclude the target words when they were unaware of them at the time they were presented. Thus, at the 0 -min retention interval, performance on the aware trials was significantly below the baseline level of performance, indicating perception with awareness, whereas on the unaware trials, performance was significantly above the baseline level of performance, indicating perception without awareness. In contrast, at both the 16-min and the 32-min retention intervals, performance on both the aware and unaware trials was significantly above the baseline level of performance. Thus when memory was assessed following the 16-min and 32-min retention intervals, no matter whether the participants indicated that they perceived the words with awareness or without awareness, they were generally unable to exclude the words from their stem completions.

The most important result in Experiment 3 is the finding showing that there is definitely memory following the 32-min retention interval for words perceived without awareness. Thus, Experiment 3 establishes that memory for information perceived without awareness can persist for at least 32 minutes, and suggests the possibility that memory for information perceived without awareness may persist for longer than 32 minutes. 


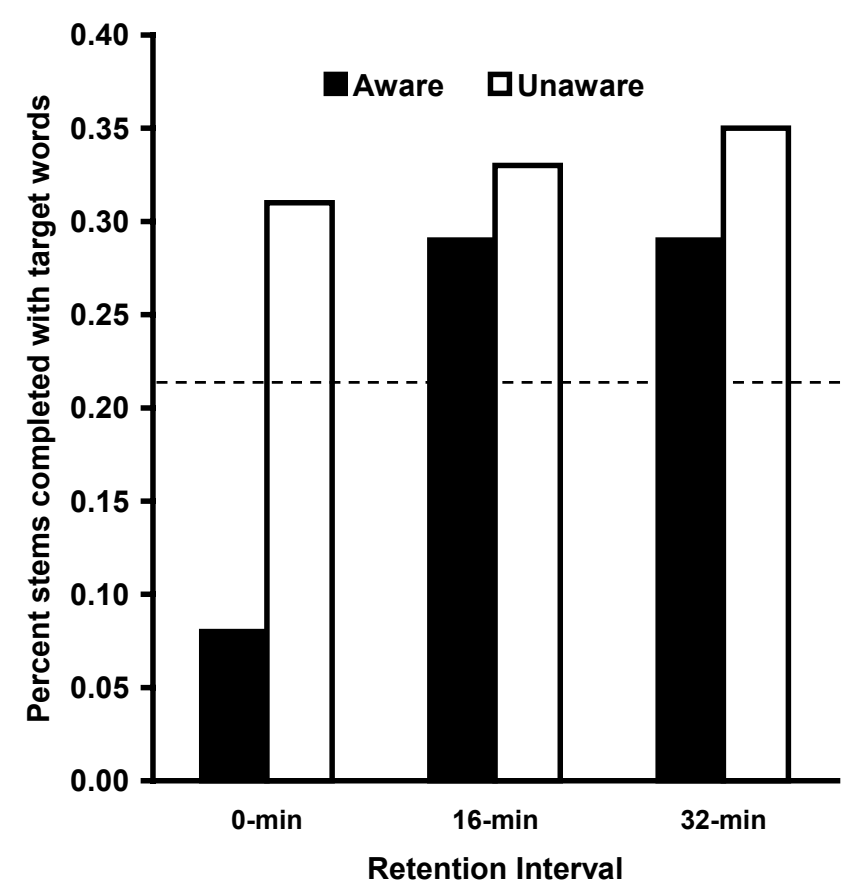

Fig. 5. Experiment 3: Percent of stems completed with target words following the 0-min, 16-min, and 32-min retention intervals. Dotted line indicates the baseline level of performance.

Obviously, what is needed are studies in which memory for information perceived without awareness is assessed following temporal intervals measured in hours, days, or weeks. Studies of memory for events during anaesthesia provide evidence that is particularly relevant. In many of these studies, memory for information presented during general anaesthesia has been assessed over delays measured in hours or days. It is these studies that we turn to next.

\section{Memory for events during anaesthesia}

Studies of memory for events during anaesthesia provide a useful avenue for exploring perception without awareness. Even though surgical patients who have been administered general anaesthesia are not supposed to have any post-surgical memory for events during anaesthesia, as early as 1961, 
there were researchers who claimed to have found evidence of memory for events during anaesthesia. For example, Pearson (1961) reported that positive suggestions during anaesthesia decreased the duration of hospitalization following surgery, and Hutchings (1961) reported that positive suggestions reduced the pain following surgery.

Even more compelling was Levinson's (1965) observation that patients perceived and remembered significant events that occurred during anaesthesia. Levinson staged a mock crisis while surgical patients were under the influence of general anaesthesia. During surgery, 10 anesthetized patients had the following statement recited to them.

"Just a moment! I don't like the patient's colour. Much too blue. Her lips are very blue. I'm going to give a little more oxygen. . . . There, that's better now. You can carry on with the operation." (Levinson, 1965, p. 544)

One month following surgery, Levinson hypnotized the patients to see whether they could remember anything that may have occurred while they were anesthetized. Surprisingly, 4 of the 10 patients were able to provide an almost verbatim account of the statement made during the mock crisis, and another 4 patients had some memory of the message. The results of these early studies certainly suggest that patients may have memory for events during anaesthesia.

Not surprisingly, the findings reported by Pearson (1961), Hutchings (1961), and Levinson (1965) generated considerable interest and motivated additional studies. However, despite a considerable number of studies over the next 40 years, based on a variety of experimental procedures, the findings showed a confusing picture of significant and nonsignificant results. For this reason, Merikle and Daneman (1996) decided to conduct a meta-analysis of all relevant studies investigating memory for specific information during anaesthesia. The advantage of using meta-analytic techniques is that they provide a method for combining and quantifying the results of individual studies so that it is possible to see the general trends across all relevant studies. The primary goal of the meta-analysis was to establish whether the overall pattern of findings provided any support for the view that there is memory for specific information presented during general anaesthesia.

The meta-analysis was based on the results of 29 different studies involving a total of 1492 surgical patients. The results are shown in Figure 6 , which shows the average effect sizes summed across direct and indirect measures at three different temporal intervals following surgery. Each effect size is represented by a correlation coefficient $(r)$ and reflects the degree of association between the manipulated variable (e.g., old vs. new 


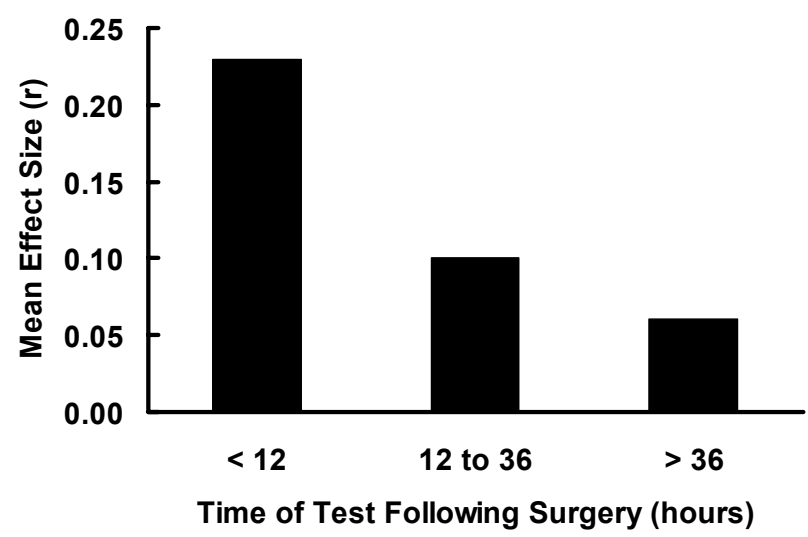

Fig. 6. Mean effect size of memory for information presented during anaesthesia when tested at different temporal intervals following surgery (adapted from Merikle \& Daneman, 1996).

words in forced-choice recognition) and performance on the memory test (e.g., forced-choice recognition). The three temporal intervals reflect common research strategies. In 12 studies involving a total of 708 patients, the strategy was to measure memory as soon as possible after the patients regained consciousness (i.e., less than 12 hours following surgery), whereas in 10 studies involving a total of 560 patients, the strategy was to test patients approximately 1 day following surgery (i.e., between 12 and 36 hours following surgery). In the 7 remaining studies involving 224 patients, the memory tests were administered more than 36 hours following surgery, including some instances in which the memory tests were administered more than 2 weeks following surgery.

The pattern of findings shown in Figure 6 is clear: The average effect size decreased systematically as the interval between the end of surgery and administration of the memory test increased. Statistical analyses of the effect sizes indicated that the average effect sizes were statistically significant when memory was tested either less than 12 hours following surgery or between 12 and 36 hours following surgery. However, the very small effect size when memory was tested more than 36 hours following surgery was not significant. Assuming that the patients were truly unaware during surgery/anaesthesia, these findings provide strong support for the conclusion that the impact of information perceived without awareness can last for a considerable period of time. 
One question which can be raised regarding the findings reported by Merikle and Daneman (1996) is whether the evidence showing memory for events during anaesthesia may actually reflect perception with awareness during brief episodes of consciousness during surgery. It is well known that the depth of anaesthesia during surgery varies. Although anaesthesiologists strive to maintain a level of anaesthesia adequate to ensure that a patient experiences no awareness during surgery, it is always possible that some patients may experience brief periods of awareness, which they subsequently do not and cannot consciously recollect. If critical to-beremembered materials happened to be presented during the brief periods of awareness that some patients may experience, then the evidence from the meta-analysis showing memory for events during anaesthesia may actually reflect memory following perception with awareness rather than memory following perception without awareness.

Fortunately, this question has been addressed in a recent study in which the bispectral index (BIS) ${ }^{1}$ was used to monitor the depth of anaesthesia during surgery involving trauma patients (Lubke, Kerssens, Phaf, \& Sebel, 1999). For trauma patients as a group, there is considerable variation in the depth of anaesthesia. Generally, the more serious the trauma the poorer is the tolerance for anaesthetic agents. As a consequence, less anaesthesia is typically administered to patients with serious trauma than to patients with minor trauma. For this reason, patients with serious trauma are more likely to experience awareness during surgery than patients with minor trauma (Bogetz \& Katz, 1984). Thus, as a group, trauma patients are ideal for studying the relation between depth of anaesthesia and subsequent memory for events during anaesthesia.

During anaesthesia, Lubke et al. (1999) presented trauma patients with 16 target words. Each target word was repeated 40 times in succession with a two-sec delay between repetitions, with the total duration of the presentation of each target word being three minutes. Subsequently, the corresponding three-minute recording of the EEG associated with the presentation of each target word was identified; in this way, it was possible to compute the BIS for each of the 16 target words. Consequently, it was possible to establish the depth of anaesthesia for each target word at the time it was presented.

\footnotetext{
${ }^{1}$ It has proven difficult to develop an objective indicator of the depth of anaesthesia. To date, monitoring the depth of anaesthesia during surgery has relied primarily on the clinical judgments of anaesthesiologists. The BIS is a promising development. It is based on real-time analysis of the electroencephalogram, and has been found to correlate well with clinical judgments of the depth of anaesthesia.
} 


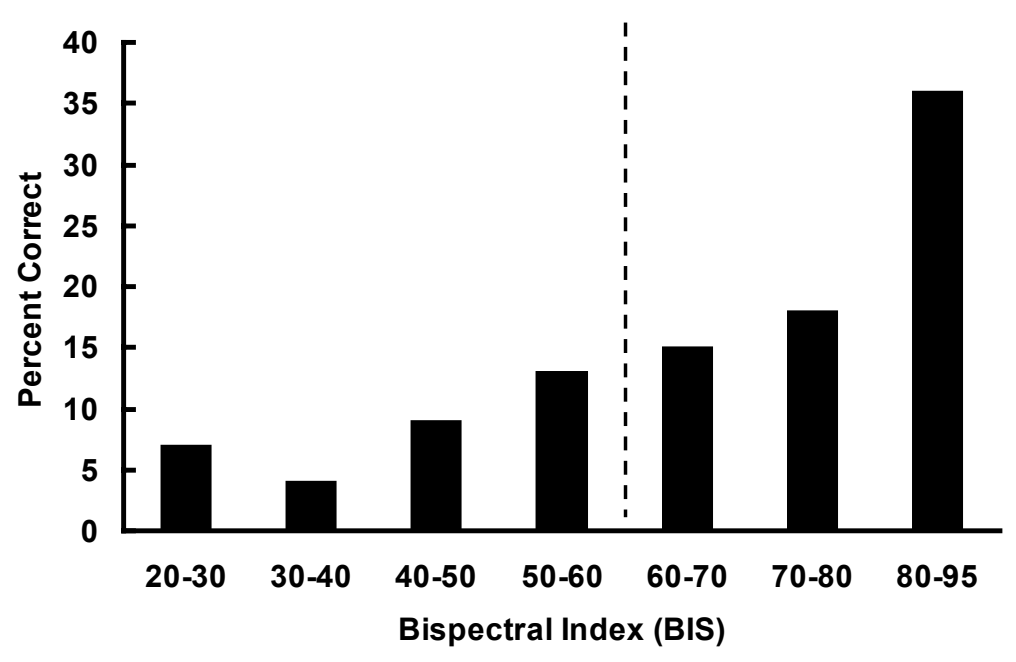

Fig. 7. Mean percent correct stem-completion performance for words presented at different depths of anaesthesia as indicated by the bispectral index. Dotted line indicates level of BIS associated with adequate anaesthesia. (adapted from Lubke et al., 1999).

Lubke and her colleagues (1999) assessed memory for events during anaesthesia by asking the patients to complete word stems with the target words. Figure 7 shows the mean percentage of stems completed with the target words at different depths of anaesthesia, as indicated by the value of BIS. The lower the value of BIS, the greater is the depth of anaesthesia. Two conclusions emerge from a consideration of the findings presented in Figure 7. First, memory for the target words decreased as the BIS decreased; in other words, memory decreased as the depth of anaesthesia increased. Second, there was some memory at all levels of BIS. Critically, the results indicated that there was memory for events during anaesthesia at BIS values between 40 and 60, which are considered by anaesthesiologists to indicate sufficient anaesthesia to prevent all awareness of events during anaesthesia. Thus, the findings reported by Lubke and her colleagues clearly show memory for events during anaesthesia which cannot be attributed to periods of awareness or consciousness during surgery.

Taken together, the results of the meta-analysis reported by Merikle and Daneman (1996) and the results reported by Lubke et al (1999) point to the same conclusion. Namely, when information is presented to patients during general anaesthesia, some patients perceive some of the information without any awareness of perceiving. In addition, the results of the meta- 
analysis indicate that memory for events during anaesthesia can persist for at least 24 hours. There is also reason to believe that the impact of information perceived without awareness during anaesthesia may extend beyond 24 hours. One limitation of all studies included in the meta-analysis is that the stimulus materials did not have personal relevance for the patients. The typical stimulus materials were single words, and memories for single words, especially relatively high-frequency words, are subject to considerable decay and interference. Thus, it is not particularly surprising that the memories of single words may have lasted only a few hours. If more personally relevant materials had been used in these studies, such as the mock crisis staged by Levinson (1965), then it is possible that the impact of information perceived during anaesthesia might have extended over temporal intervals measured in days or weeks.

\section{Concluding comments}

Both our studies and the studies of memory for events during anaesthesia point to the same conclusion: Information perceived without awareness can have an impact for a considerable period of time. Thus, perception without awareness can potentially have important consequences regarding how people consciously experience the world about them (see Merikle et al., 2001).

Our conclusion stands in stark contrast to the conclusion reached by Greenwald and his colleagues (1996). On the basis of the results of a series of semantic-priming experiments, they concluded that the impact of information perceived without awareness lasts for $100 \mathrm{~ms}$ or less! There is no doubt about their findings. However, the important question is whether their conclusion generalizes beyond their experiments. We believe that it does not and that the radically different conclusions suggested by their studies and our studies reflects a fundamental difference in the way awareness was assessed.

The success of any study of perception without awareness depends critically on the behavioural measure used to assess awareness. In general, there are two different approaches to the assessment of awareness. One approach is to base the assessment of awareness on the participants' reports of their conscious experiences. Such measures are commonly referred to as subjective measures of awareness (see Reingold \& Merikle, 1990). Both our studies and Mack and Rock's (1998) studies are based on subjective measures of awareness whereby participants - through reports of their conscious experiences - provide direct assessments of their aware- 
ness of critical stimuli. Likewise, if surgical patients report that they were unaware of any events during surgery, anaesthesiologists assume that they were in fact unaware of events during surgery.

In contrast to subjective measures, other approaches to the study of perception without awareness, such as the approach followed by Greenwald and his colleagues (1996), are based on objective measures of awareness. With objective measures, awareness is assessed in terms of performance on tasks such as stimulus detection or forced-choice recognition. When stimulus detection or forced-choice recognition approximate a chance level of performance, it is assumed that participants have no awareness whatsoever of critical stimuli.

In general, objective measures of awareness provide misleading estimates of the minimum stimulus conditions needed to perceive a stimulus with awareness. In studies based on objective measures, it is assumed that a failure to discriminate between alternative stimuli indicates that participants are unaware of the characteristics that distinguish the stimuli. This is a relatively non-controversial assumption which is completely consistent with subjective experience. However, a second, unjustifiable assumption, which is not consistent with subjective experience, is often made. The second assumption is that success in discriminating between alternative stimuli necessarily indicates awareness of the characteristics that distinguish the stimuli (e.g., Greenwald et al., 1996; Holender, 1986; Kouider \& Dupoux, 2004). This second assumption (a) does not necessarily follow from the first assumption, (b) is unsupported by any evidence, and (c) is completely inconsistent with subjective experience. In fact, the only direct evidence regarding whether it is possible to discriminate between alternative stimulus states when there is no awareness of perceiving comes from studies in which awareness has been assessed with subjective measures (e.g., Cheesman \& Merikle, 1986; Sidis, 1898). The results of these studies clearly show that participants can discriminate between alternative stimulus states even when they report that they are unaware of the stimuli.

The critical difference between subjective and objective measures of awareness is that objective measures generally provide much more conservative estimates of the minimal stimulus conditions leading to perception with awareness than is provided by subjective measures. Therefore, it is not particularly surprising that studies based on objective measures provide much shorter estimates of the duration of the influence of information perceived without awareness than is provided by studies based on subjective measures. Given that all measures of perception can in principle be influenced both by information perceived with awareness and by information perceived without awareness, the minimal stimulus conditions established using objective measures not only reduce the likelihood of perception with 
awareness but also reduce the likelihood of perception without awareness. For this reason, subjective measures provide a more accurate measure of the presence or absence of awareness than is provided by objective measures. Although there is sometimes an uneasiness regarding subjective measures, when all things are considered, self-reports of conscious experiences provide both a direct and an accurate indicator of the presence or absence of awareness (see Chalmers, 1996: Merikle, 1992).

Now that it is established that the influence of information perceived without awareness can persist for periods of time measured in hours or even days, it is important to establish more firmly both the duration of the influence of information perceived without awareness and the types of influences that information perceived without awareness can have on other cognitive processes As already mentioned, one limitation of most studies to date is that they have only evaluated the impact of stimulus information which has little personal relevance to the participants (e.g., single words). Given the suggestive evidence that the impact of information perceived without awareness may last for relatively long periods of time if the perceived information has personal relevance (e.g., Levinson,1965), a challenge for the future is to find ways to study the impact of information with high personal relevance when it is perceived without awareness. Another challenge is to establish how information perceived without awareness influences other cognitive processes. It is known that information perceived without awareness can influence both what stimuli are perceived with awareness and how stimuli perceived with awareness are consciously experienced (e.g., Merikle et al., 2001). However, to date there are relatively few studies of the impact of information perceived without awareness. Given that information perceived without awareness can have an impact over considerable periods of time, it is now important to investigate the limits of the impact of information perceived without awareness both on other cognitive processes such as attention, perception, memory, and decision making, and on conscious experience in general.

\section{Author Notes}

The research was supported by a discovery grant from the Natural Sciences and Engineering Research Council of Canada awarded to the first author, and by a postgraduate scholarship from the Natural Science and Engineering Research Council of Canada to the second author. 
Correspondence should be addressed to Philip M. Merikle, Department of Psychology, University of Waterloo, Waterloo, Ontario, Canada N2L 3G1. E-mail: pmerikle@uwaterloo.ca.

\section{References}

Bogetz, M. S., \& Katz, J. A. (1984). Recall of surgery for major trauma. Anesthesiology, 61, $6-9$.

Chalmers, D. J. (1996). The conscious mind. New York: Oxford University Press.

Cheesman, J., \& Merikle, P. M. (1986). Distinguishing conscious from unconscious perceptual processes. Canadian Journal of Psychology, 40, 343-367.

Debner, J. A., \& Jacoby, L. L. (1994). Unconscious perception: Attention, awareness, and control. Journal of Experimental Psychology: Learning, Memory, and Cognition, 20, 304-317.

Greenwald, A. G., Draine, S. C., \& Abrams, R. L. (1996). Three cognitive markers of unconscious semantic activation. Science, 273, 1699-1702.

Holender, D. (1986). Semantic activation without conscious identification in dichotic listening, parafoveal vision, and visual masking: A survey and appraisal. Behavioral and Brain Sciences, 9, 1-23.

Hutchings, D. D. (1961). The value of suggestion given under anesthesia: A report and evaluation of 200 consecutive cases. American Journal of Clinical Hypnosis, 4, 26-29.

Kouider, S., \& Dupoux, E. (2004). Partial awareness creates the "illusion" of subliminal semantic priming. Psychological Science, 15, 75-81.

Levinson, B. W. (1965). States of awareness during general anaesthesia. British Journal of Anaesthesia, 37, 544-546.

Lubke, G. H., Kerssens, C., Phaf, H., \& Sebel, P. H. (1999). Dependence of explicit and implicit memory on hypnotic state in trauma patients. Anesthesiology, 90, 670-680.

Mack, A., \& Rock, I. (1998). Inattentional blindness. Cambridge, MA: MIT Press.

Merikle, P. M. (1992). Perception without awareness: Critical issues. American Psychologist, 47, 792-795.

Merikle, P. M., \& Daneman, M. (1996). Memory for unconsciously perceived events: Evidence from anesthetized patients. Consciousness and Cognition, 5, 525-541.

Merikle, P. M., \& Joordens, S. (1997). Parallels between perception without awareness and perception without attention. Consciousness and Cognition, 6 , 219-236.

Merikle, P. M., Joordens, S., \& Stolz, J. A. (1995). Measuring the relative magnitude of unconscious influences. Consciousness and Cognition, 4, 422-439.

Merikle, P. M., Smilek, D., \& Eastwood, J. D. (2001). Perception without awareness: Perspectives from cognitive psychology. Cognition, 79, 115-134. 
Pearson, R. E. (1961). Response to suggestion given under general anesthesia. American Journal of Clinical Hypnosis, 4, 106-114.

Reingold, E. M., \& Merikle, P. M. (1990). On the inter-relatedness of theory and measurement in the study of unconscious processes. Mind \& Language, 5, 928.

Sidis, B. (1898). The psychology of suggestion. New York: D. Appleton. 
